\title{
USO DA RADIAÇÃO SOLAR NA DESINFECÇÃO DA ÁGUA DE POÇOS RASOS*
}

\section{L.A. A maral, A .P. N unes, J. Castania, C.S. Lorenzon, L.S.S. Barros, A. N ader Filho}

Universidade Estadual Paulista, Faculdade de Ciências A grárias e Veterinárias, Departamento de M edicina Veterinária Preventiva eReprodução A nimal, Via de A cesso Prof. Paulo Donato Castellane, s/ №, CEP 14884900, Jaboticabal, SP, Brasil. E-mail: lamaral @fcav.unesp.br

RESUMO

Com o objetivo de avaliar a eficiência da exposição à radiação solar na desinfecção da água, amostras deáguadepoços rasosforamacondicionadas em garrafas "PET" (PolietilenoTeraftalato) com volume de $2.000 \mathrm{~mL}$, e expostas ao sol por 2, 5 e 12h. A ntes da exposição, após a exposição e em amostras que permaneceram 2, 5 e $12 \mathrm{~h}$ protegidas do sol (controles) foram determinados os números mais prováveis de coliformes totais eEscherichia coli e os números de microrganismos mesófilos. Foi verificado aindao recrescimento bacteriano após $72 \mathrm{~h}$ da exposição ao sol emamostras protegidas daaçãodaluz solar eaquantidadedeenergia recebida pelasamostrasapósostrêstempos deexposição àradiação solar. Osresultadosobtidosevidenciaram quea radiação solar foi eficaz na desinfecção da água com reduções, após $12 \mathrm{~h}$ de exposi ção, de 98,2\%, 99,9\% e 100\% nos números demicrorganismos mesófil los, col iformestotais eE. coli, respectivamente. Foi verificadaaausência derecrescimento detodosmicrorganismospesquisadosapós $12 \mathrm{~h}$ deexposição ao sol.Osresultados evidenciaram que a exposição à radiação solar da água de consumo humano, acondicionada em garrafas PET, podeser utilizada para diminuir o risco deenfermidades deveiculação hídrica.

PALAVRAS-CHAVE: Radiação solar, qualidade deágua, desinfecção, Escherichia coli.

\section{ABSTRACT}

SOLAR RADIATION IN THE DISINFECTION OF SHALLOW WELL WATER. This study evaluated the effictiveness of expusure to solar radiation for disinfecting water samples from shal low wells. Water samplewereplaced into 2-liter PET (PolyethyleneTerephthal ate) exposed to sun rays for 2, 5 and 12 hours. Probably numbers of total coliform bacteria, Escherichia coli and mesophyl microorganisms were determined before and after exposure to sun and in samples protected from the sun (controls) for 2, 5 and 12 hours. Bacterial re-growth after a $72 \mathrm{~h}$-exposureto the sun in samples which wereprotected from the sun rays and theamount of energy received by thesamples after thethreeexposureperiods to sun radiation wereal so evaluated. Results showed that sun radiation was effective for water disinfection with $98.2 \%, 99.9 \%$ and $100 \%$ reductions in mesophyl microorganisms, total col iform bacteria and $\mathrm{E}$. coli respectively after a $12 \mathrm{~h}$-exposureto sun rays. Lack of re-growth of all microorganisms analyzed after a $12 \mathrm{~h}$ exposureto sun rays was confirmed. Results showed that exposure of water placed in PET bottles for human consumption may beused to diminish water-transmitted diseaserisks.

KEY WORDS: Solar radiation, water qual ity, disinfection, Escherichia coli.

INTRODUÇÃO

A água é o mais importante recurso natural do mundoesemelaavidanão podeexistir. Em 1854uma epidemia decóleraemLondres causou 10.000 mortes erelacionou pela primeira vez uma doença com contaminação daáguadeconsumo porbactériasentéricas através da poluição da mesma por esgoto doméstico (BATES, 2000).
Em relação a água de consumo humano, ISAACMARQUEZ et al . (1994) afirmam que ela éum dos mais importantes veículos de enfermidades diarreicas de natureza infecciosa, tornando-seprimordial a avaliação da sua qualidade microbiológica.

Dentre os mananciais de água subterrânea utilizados no meio rural nos Estados Unidos os poços rasos eas minas representam quase $100 \%$ das fontes de abastecimento individual cujas águas não são

*Trabal ho financiado pela Fundação de A mparo à Pesqui sa do Estado de São Paulo - FA PESP. 
tratadas nem monitoradas regularmente, colocando em risco a saúde da população consumidora (Sworobuck et al., 1987; CAson et al., 1991). Em nosso paísa situação ésemel hante, ressaltando-sea afirmação de HoffmAnn et al . (1994) queno Brasil a proteção daságuassubterrâneastem sido negligenciada, apesar de sua grande importância do ponto de vista econômico e estratégico sendo, portanto, necessária uma maior proteção contra as diversas fontes de contaminação das mesmas.

AmAral et al . (1994), anal isando amostras deágua depoçosrasos, localizadosnazona urbanado Município deJaboticabal, SP, encontraram 92,1\%dasamostrasforadospadrõesmicrobiológicos depotabilidade para consumo humano. A mARAL et al. (2000) em estudo realizado em propriedades suinícolas, situadas na região nordeste do Estado de São Paulo, verificaram que $62,5 \%$ das amostras das fontes de abastecimento estavam fora dos padrões de potabilidadeem decorrência da presença de coliformes totais e coliformes fecais nas amostras analisadas.

GALBRAITH et al . (1987) citamquede1937a1986, no ReinoUnido, 43,0\% dossurtosdedoenças veiculadas pela água foram em decorrência daingestão deágua oriunda de fontes privadas, afetando em torno de 2.000 pessoas. EmBIL et al. (1984) e Dennis et al. (1993) verificaram na Nova Escócia e Inglaterra relações positivas entre consumo deágua oriunda de poçose a prevalência de giardíase e parasitimo por A scaris lumbricoides, respectivamente, enquanto BERGEISEN et al . (1985) relacionaramaocorrência desurto dehepatiteA, nosEstadosUnidos, como consumo deáguade minas não tratadas.

O processo dedesinfecção pela energia solar tem 2 componentes princi paisaluz ultravioleta, queirradia os microrganismoseinduz a formação deformas reativas de oxigênio ea radiação infra-vermelha que aquecea água. J orce et al. (1996) obtiverameliminação da Escherichia coli em amostras de água de baixa turbidez após 7h de exposição solar daágua contida em garrafas transparentes com volume de $2.000 \mathrm{~mL}$.

Segundo WegELIn etal. (1994) para quea desinfecção pela luz solar seja eficiente a água a ser desinfe tada deve apresentar turbidez < 30 NTU. ReED et al. (2000) avaliando a eficiência da energia solar na inativação de bactérias de origem fecal em trabalho realizado naíndia ena África do Sul verificaram que a agitação vigorosa do frasco deágua, incorporando oxigênio, aumenta bastante a capacidade de desinfecção verificando a inativação completa desses microrganismosentre3e6h deexposição daáguaao sol .

Conroy et al. (1999) em estudo real izado com 349 crianças da comunidade Maasai na África verificaram queo consumo deáguatratada pela exposição ao sol reduziu demaneirasignificativa o risco do apare cimento de diarréias nos que consumiram água ex- posta ao sol quando comparados com os que consumiram a água sem a exposição. Conroy et al. (2001) afirmam quea desinfecção solar da água podeauxiliar muito no controle de epidemias de cólera.

O presentetrabal ho tevecomo objetivosverificara efi cácia da utilização da radiação solar na desinfecção de água de poços rasos contaminadas naturalmente por microrganismos indicadores, a possível existência do recrescimento bacteriano após a desinfecção e fornecer subsídios para a aplicação desse método de desinfecção com base na quantidade de energia recebida pela água e inativação dos microrganismos pesquisados.

\section{MATERIAL E MÉTODOS}

Foram anal isadas 30 amostras deágua oriundas de30poços rasos, já conheci doscomo demáqualidademicrobiológica daágua, local izadosno mei orural do M unicípio de Jaboticabal, SP. As amostras foram expostas ao sol, na posição horizontal, em volumes de $2 \mathrm{~L}$ acondicionados em garrafas PET (Polietileno Tereftalato) transparentes, por $2 \mathrm{~h}, 5 \mathrm{~h}$ e $12 \mathrm{~h}$ e, parale lamente, foram deixadas 30 amostras protegidas do sol , pelo mesmo período, queserviram como controle. A pós 72h daexposição asamostrasforamprotegi das da ação do sol e foi verificado o recrescimento bacteriano em 10 amostras, de modo a se obter 10 repetiçõesem cadaum dostempos, em decorrênciada possibilidade da reativação no escuro por reparo do DNA lesado pela radiação UV.

\section{Diluiç̧ão das amostras}

As amostras de água, expostas ao sol eos controles, foram diluídas em água peptonada a 0,1\% esterilizada, adicionando-se $10 \mathrm{~mL}$ em $90 \mathrm{~mL}$ do diluente, obtendo-se a diluição $10^{-1}$. A partir dessa primeira diluição foram obtidas as diluições sucessivas.

D eterminação do número mais provável (N M P) de coliformes totais e Escherichia coli (A PHA, 1992)

A amostradeáguaou suadiluição ( $100 \mathrm{~mL}$ ) foram misturadas ao meio de cultura (Colilert) e após homogeneização, asmisturasforamtransferidaspara a cartel a Quanti-tray eselada em seladora específica. Em seguida, as cartelas foram incubadas a 35으 por 24h. A seguir foi real izadaadeterminação do número de coliformes totais através da contagem das células com coloração amarel aeutilização detabel aprópria. O número deE . coli foi determinado pelo número de células que apresentarem fluorescência após incidirem-seraiosUV sobrea cartela, utilizando-sea mesma tabela para coliformes totais. 


\section{Q uantificação dos microrganismos mesófilos pelo método de "pour plate" (A PH A, 1992)}

Foi utilizadaasemeaduraemprofundidadecomo meio de cultura àgar padrão para contagem (PCA) e incubação a $35^{\circ} \mathrm{C}$ por 48 .

\section{D eterminaçãodosteoresdeturbidez (A PH A, 1992)}

Osteores deturbidez dasamostras deáguaforam obtidosatravés dautilização do Turbidímetro HACH model o $2100 \mathrm{~A}$, que usa o método nefelométrico com tubos de formazina para a padronização. Os método é equivalente aos descrito em APHA (1992) e os resultados foram expressos em UNT (Unidade Nefelométrica deTurbidez).

\section{Radiação solar global}

Dados de radiação solar foram fornecidos pelo Laboratório de Instrumentação Aquisição e Processamento(LIAP) do Departamento deEngenhariaRural daFCAV/ UNESP, Câmpus de Jaboticabal, SP.

Para determinação da radiação solar global o LIAP possui, em sua área experimental, um piranômetrocomcompensação detemperaturaeuma constante de cal ibração de 12,80.10-6V/ W. $\mathrm{m}^{-2}$. Esse sensor estáfixado sobreuma plataforma dealumínio presaaum cano galvanizadochumbadonochão, que o mantém na horizontal, \1,50 m acima de uma superfície gramada.

Os sinais em $\mathrm{mV}$ deste equipamento são tratados por um Sistema de Aquisição de Dados (CR10 Measurement \& Control System) obtendo-se por integração o total de radiação solar global a cada 15 minutos.

\section{A nálise estatística}

Os resultados obtidos dos números de microrganismos nos diferentes tempos de exposição foram analisados pelo teste Tukey a $5 \%$ de probabilidade (Stell \& ToRRIE, 1960).

\section{RESULTADOS}

O Tabela 1 apresenta os valores das médias geométricas dos números mais prováveis de coliformes totais e fecais e dos números de microrganismos mesófilos das amostras de água dos poços antes da exposição (tempo zero), dos controles edas amostras expostas ao sol após $2 \mathrm{~h}, 5 \mathrm{~h}$ e $12 \mathrm{~h}$.

A Tabela2apresenta os valores das porcentagens deredução nos números de coliformes totais, E. coli e microrganismos mesófilos, em relação aos controles, ea quantidade deenergia, nas amostras expostas ao sol por $2 \mathrm{~h}, 5 \mathrm{~h}$ e $12 \mathrm{~h}$.

A Tabela 3apresenta osvalores das porcentagens deredução nos números de coliformes totais, E. coli e microrganismos mesófilos, em relação a água antes da exposição (tempo zero), e as quantidades médias deenergia, nas amostras expostas ao sol por $2 \mathrm{~h}$, 5h e $12 \mathrm{~h}$.

A Tabela4apresenta asporcentagensdeamostras foradospadrõesmicrobiológicos, portaria518de25/ 3/ 2004 do Ministério da Saúde paraE. coli emicrorganismos mesófilos nas amostras de água antes da exposição (tempo zero) eapós $2 \mathrm{~h}$, $5 \mathrm{~h}$ e $12 \mathrm{~h}$ deexposição ao sol.

A Tabela 5 apresenta as médias geométricas do recrescimento bacteriano, após $72 \mathrm{~h}$, de coliformes totais, E. coli e microrganismos 70 As quantidades médias de energia recebidas pelas amostras após $2 \mathrm{~h}$, $5 \mathrm{~h}$ e $12 \mathrm{~h}$ deexposição ao sol foram 1.041,33KJ/ $\mathrm{m}^{2}, 5.134,18 \mathrm{KJ} / \mathrm{m}^{2}$ e $10.392,51 \mathrm{KJ} / \mathrm{m}^{2}$, respectivamente.

Os valores mínimo, médio emáximo da turbidez nas amostras deágua foram; 0,38 NTU, 1,15 NTU e 2,1 NTU, respectivamente, estando portanto dentro dolimiteparapotabilidadehumanade5NTU (BRASIL, 2004).

\section{DISCUSSÃO}

Observa-senas Tabelas 1, 2 e3, no que se refereà E. coli, queaexposição ao sol daágua dos poços rasos foi suficientepara diminuir muito o risco representado pela água à saúde do consumidor jáa partir de $5 \mathrm{~h}$ deexposição, umavez queapresentou redução média desse indicador superior a 90\%. Ressalta-se que as diferenças nos números deE. coli nasamostrasexpostas ao sol econtroles foram significativas $(p<0,05)$ a partir de2h deexposição. Observa-senaTabela2que após $5 \mathrm{~h}$ deexposição a quantidademédia deenergia recebida pela água contida nas garrafas foi $5.134,18$ $\mathrm{Kj} / \mathrm{m}^{2}$ esegundo W EGELIN etal. (1994) umaquantidade de $2.000 \mathrm{Kj} / \mathrm{m}^{2}$ de radiação solar por $5 \mathrm{~h}$ causou a redução de $99,9 \%$ nos números de $\mathrm{E}$. coli.

Osbonsresultadosobtidosnopresenteestudo vão ao encontro da afirmação deM cGuIGAN et al . (1998) de quea desinfecção solar em regiões degrande insolação é um método eficiente, de baixo custo para a mel hora da qualidade da água de bebida e deve ser utilizadasemáreascarentes desaneamento básico. A esserespeito, KeHOE et al . (2004) citamqueautilização da desinfecção solar da água de bebida é uma intevenção aproriada para ser aplicada, principalmente em países em desenvolvimento, durante um surto deShigella dysenteriae. 
Tabela 1- Valores das médias geométricas dos números mais prováveis/ $100 \mathrm{~mL}$ decol iformes totais eE. coli enúmeros de microrganismos mesófilos por $\mathrm{mL}$ nas amostras de água no tempo zero, e após $2 \mathrm{~h}$, $5 \mathrm{~h}$ e $12 \mathrm{~h}$ expostas à sombra (controles) eao sol.

\begin{tabular}{lccccccc}
\hline Microrganismo & $\begin{array}{c}\text { Água tempo } \\
\text { zero }\end{array}$ & $\begin{array}{c}\text { Agua 2h na } \\
\text { sombra } \\
\text { (controle) }\end{array}$ & $\begin{array}{c}\text { Agua 2h } \\
\text { no sol }\end{array}$ & $\begin{array}{c}\text { Agua 5h na } \\
\text { sombra } \\
\text { (controle) }\end{array}$ & $\begin{array}{c}\text { Agua 5h } \\
\text { no sol }\end{array}$ & $\begin{array}{c}\text { Agua 12h na } \\
\text { sombra } \\
\text { (controle) }\end{array}$ & $\begin{array}{c}\text { Agua 12h } \\
\text { no sol }\end{array}$ \\
\hline Coliformestotais & $1,3 \times 10^{3}$ & $1,3 \times 10^{3 \mathrm{~A}}$ & $2,3 \times 10^{2 \mathrm{~B}}$ & $2,3 \times 10^{3 \mathrm{~A}}$ & $0,15 \times 10^{\mathrm{B}}$ & $2,1 \times 10^{3 \mathrm{~A}}$ & $0,06 \times 10^{\mathrm{B}}$ \\
E. coli & $7,5 \times 10^{2}$ & $7,4 \times 10^{2 \mathrm{~A}}$ & $2,3 \times 10^{2 \mathrm{~B}}$ & $1,4 \times 10^{3 \mathrm{~A}}$ & $0,1 \times 10^{\mathrm{B}}$ & $1,1, \times 10^{3 \mathrm{~A}}$ & $0^{\mathrm{B}}$ \\
Mesófilos & $4,8 \times 10^{3}$ & $4,8 \times 10^{3 \mathrm{~A}}$ & $1,2 \times 10^{3 \mathrm{~A}}$ & $1,9 \times 10^{4 \mathrm{~A}}$ & $1,1 \times 10^{3 \mathrm{~B}}$ & $4,4 \times 10^{4 \mathrm{~A}}$ & $8,3 \times 10^{2 \mathrm{~B}}$ \\
\hline
\end{tabular}

Namesmalinha, nas comparaçõesentrecontroleeexposição ao sol, nos diferentestempos deexposição, letras diferentes representamsignificânciaao nível de $5 \%$.

Tabela2-Reduçõesporcentuais, emrelação aoscontroles, nos números mais prováveis de col iformes totais eE. coli enosnúmerosdemicrorganismosmesófilosequantidade média de energia após $2 \mathrm{~h}$, $5 \mathrm{~h}$ e $12 \mathrm{~h}$ de exposição ao sol.

\begin{tabular}{lccc}
\hline Microrganismo & $\begin{array}{c}\text { Agua 2h } \\
\text { no sol }\end{array}$ & $\begin{array}{c}\text { Agua 5h } \\
\text { no sol }\end{array}$ & $\begin{array}{c}\text { Agua } 12 \mathrm{~h} \\
\text { no sol }\end{array}$ \\
\hline Coliformes totais & 84,80 & 99,0 & 99,9 \\
E. coli & 69,1 & 99,9 & 100 \\
Mesófilos & 75 & 42,2 & 98,2 \\
EnergiaKj/ $\mathrm{m}^{2}$ & $1.041,33$ & $5.134,18$ & $10.392,51$ \\
\hline
\end{tabular}

Tabela3-Reduçõesporcentuais, em rel ação aT0 (água "in natura"), nosnúmerosmais prováveisdecoliformestotais eE. coli enosnúmeros demicrorganismosmesófilosapós 2h, 5h e 12h de exposição ao sol.

\begin{tabular}{lccc}
\hline Microrganismos & $\begin{array}{c}\text { Água 2h } \\
\text { no sol }\end{array}$ & $\begin{array}{c}\text { Água 5h } \\
\text { no sol }\end{array}$ & $\begin{array}{c}\text { Água } 12 \mathrm{~h} \\
\text { no sol }\end{array}$ \\
\hline Coliformestotais & $84,1^{\mathrm{A}}$ & $99,9^{\mathrm{B}}$ & $99,9^{\mathrm{B}}$ \\
E. coli & $69,1^{\mathrm{A}}$ & $99,9^{\mathrm{B}}$ & $100^{\mathrm{B}}$ \\
Mesófilos & $75,0^{\mathrm{A}}$ & $77,1^{\mathrm{A}}$ & $82,7^{\mathrm{A}}$ \\
\hline
\end{tabular}

Namesmalinha, letras diferentes, representamsignificância ao nível de $5 \%$.

Tabela 4 - Porcentagens de amostras fora dos padrões microbiológicos, portaria518de25/3/2004do Ministério da Saúde, para E. coli e microrganismos mesófilos nas amostras de água antes da exposição e após $2 \mathrm{~h}$, $5 \mathrm{~h}$ e $12 \mathrm{~h}$ de exposição ao sol.

\begin{tabular}{lcccc}
\hline Microrganismo & $\begin{array}{c}\text { Água } \\
\text { antes da } \\
\text { exposição }\end{array}$ & $\begin{array}{c}\text { Agua 2h } \\
\text { no sol }\end{array}$ & $\begin{array}{c}\text { Agua 5h } \\
\text { no sol }\end{array}$ & \\
& 100 & 96,3 & 14,8 & no sol \\
\hline E. coli & 100 & 70 & 70 & 70 \\
\hline
\end{tabular}

MoE et al., citados por PINFold (1990), em trabal ho realizado nas Filipinas, examinando a relação entre indicadoresbacterianosdaqualidadedaáguaediarréias em crianças verificaram que crianças que consumiram água al tamente poluída com matéria fecal (>1.000 E. coli / $100 \mathrm{~mL}$ ) tiveram uma ocorrência de diarréia significativamente maior ( $p<0,01$ ) que aquelas que consumi ramáguas com menor nível de poluição. Com $12 \mathrm{~h}$ de exposição o risco diminui ainda mais, pois foi verificada ausência dessemicrorganismo após o tratamento. Ressalta-se, queaaçãodaluz solarnasamostras deágua, expostas em garrafastipo PET incolores, pode ser uma ferramenta importantena melhoradaqualidade microbiológica da água de consumo humano em regiões com restrições na quantidade de água de boa qualidade, como por exemplo, emáreas do nordestedo nosso país, umavez quereduziu em muito o número de E. coli, microrganismo pertencente ao grupo dos coliformesfecais, queésuperior aosoutrostradicionais indicadores depoluição fecal, pois sobreviveum tempo menor no meio ambientesemel hanteaos patógenos de origem intestinal. Os coliformes totais, por exemplo, duranteasépocasmaisquentespodemsemultiplicarna águafornecendoresultadosfal sospositivos(BAudisova, 1997). Essaação positiva foi verificada por C onRoy et al. (1999) em estudo real izado com 349 crianças da comunidadeM aasai naÁ fricaverificaramqueo consumo de água tratada pela exposição ao sol reduziu demaneira significativa o risco do aparecimento de diarréias nos queconsumiramáguaexposta ao sol quando comparados com os que consumi ram a água sem a exposição.

Levando-seem conta a Portaria 518do Ministério da Saúde de 25/ 3/ 2004 (BrASIL, 2004) que considera como padrãomicrobiológico paraágua potável ausência deE . coli ou col iformesfecaispor $100 \mathrm{~mL}$ daamostra earedução, verificadaapós5h horas deexposiçãoàluz solar, de 99,9\% depreende-se que uma água de poço raso com até $9.9 \times 10^{3} \mathrm{UFC} / 100 \mathrm{~mL}$, seexposta a essa condição estaria dentro dos padrões de potabilidade referentea essemicrorganismos pois teria um número $<1,0$ microrganismo/ $100 \mathrm{~mL}$ de amostra. 
Tabel a 5-Recrescimento bacteriano, após 72h, de coliformes totais, E. coli emicrorganismosmesófilos nas amostras de água expostas ao sol por $2 \mathrm{~h}$, $5 \mathrm{~h}$ e $12 \mathrm{~h}$.

\begin{tabular}{|c|c|c|c|c|c|c|}
\hline Microrganismo & Água 2h sol & $\begin{array}{l}\text { Água } 2 \mathrm{~h} \text { sol } \\
72 \mathrm{~h} \text { depois }\end{array}$ & Água 5h sol & $\begin{array}{l}\text { Água } 5 \mathrm{~h} \text { sol } \\
72 \mathrm{~h} \text { depois }\end{array}$ & Água 12h sol & $\begin{array}{c}\text { Água } 12 \mathrm{~h} \text { sol } \\
72 \mathrm{~h} \text { depois }\end{array}$ \\
\hline Coliformes totais & $2,3 \times 10^{2}$ & $8,6 \times 10$ & $0,15 \times 10$ & $0,2 \times 10$ & $0,06 \times 10$ & 0,0 \\
\hline E. coli & $2,3 \times 10^{2}$ & $3,4 \times 10$ & $0,1 \times 10$ & $0,3 \times 10$ & 0,0 & 0,0 \\
\hline Mesófilos & $1,2 \times 10^{3}$ & $6,4 \times 10^{5}$ & $1,1 \times 10^{3}$ & $2,8 \times 10^{5}$ & $8,3 \times 10^{2}$ & $1,1 \times 10^{3}$ \\
\hline
\end{tabular}

Segundo A cra et al. (1984) aE . coli émais resistente aos efeitos letais da luz solar que outras bactérias como a Pseudomonas aeruginosa, Salmonella typhi e Salmonella enteritidis e por isso serve como bom indicador sobre o efeito da luz solar sobre bactérias entéricas.

Observa-senasTabelas 1, 2e3umamenor redução nos números de microrganismos mesófilos e coliformes totais o que pode ser explicada pela afirmação deW EGELIN et al . (1994) quemisturadediferentesmicrorganismosapresentammenossensibilidade à ação da luz solar em decorrência da presença de saprófitas mais resistentes e esporulados que são abundantes em amostras deágua contami nadas natural menteedeACRA et al . (1990) quando afirmamque quanto maior o número de microrganismos na água menor a sensibilidade dos microrganismos à radiação solar. RIJAL \& FuJIOKA (2001) citam a menor redução nos números de microrganismos mesófilos pela radiação solar quando comparada com as reduções verificadas paraE. coli e coliformes totais.

$\mathrm{Na}$ Tabela 4 pode-se verificar que após $12 \mathrm{~h}$ de exposi ção todasasamostras deáguaencontravam-se dentro do padrão para consumo humano no que se refere àE. coli. .

N o queserefereao recrescimento bacteriano após 72h, verifica-se, na Tabela 5, que ele ocorreu para os microrganismos mesófilos, uma mistura de diferentes espécies, o quetambém foi verificado por W EGELIN et al . (1994). O autor citaqueo importanteéainativação, sem recrescimento, do indicador do microrganismo patogênico como aE . coli, por exemplo, enão a obtenção de uma água estéril.

Os fatos da eliminação daE. coli ea ausência de recrescimento nas amostras deágua tratadas, Tabela 5 éde suma importância, pois BAUDISOVA (1997) concluiu que aE. coli é superior aos outros tradicionais indicadores de poluição fecal, pois sobrevive um tempo menor no meio ambiente. DAN et al. (1997) verificaram padrão desobrevivência semel hanteentre E. coli e poliovírus na água e referem-se a esse indicador como melhor queo enterococospara avaliar a poluição fecal da água.

Os val ores de turbidez da água dos poços, analisadas no presente estudo, estiveram bem abaixo do valor máximo indicado para uma boa eficiência da desinfecção solar que é de 30 NTU (Pfammatter \& WEGELIN, 1993), o que favoreceu o bom resultado na inativação dos indicadores de poluição fecal.

\section{CONCLUSÕES}

- Osresultados comprovarama eficiência daradiação solar na desinfecção da água de poços rasos, sendo queas maiores reduções ocorreram paraE. coli .

- N o presenteestudoas diferenças entreasmédias geométricas obtidas nos números deE. coli nasamostras deáguaantes da exposição sol ar, expostas ao sol econtroles (sombra) foram significativas $(p<0,05)$ a partir de $2 \mathrm{~h}$ de exposição.

- A exposição das amostras de água ao sol foi capaz decolocar todasasamostras dentro do padrão microbiológico de potabilidade paraE . coli principal indicador da possível presença de enteropatógenos.

- A exposição daáguadeconsumo humano, acondicionada em garrafas PET, àradiação sol ar podeser utilizada para diminuir o risco de enfermidades de veiculação hídrica.

\section{AGRADECIMENTOS}

À Fundação deAmparo à Pesquisa do Estado de São Paulo (FA PESP) pel o financiamento da pesquisa e ao Laboratório de Instrumentação A quisição e Processamento (LIAP) do Departamento de Engenharia Rural da FCAV/ UNESP, Câmpus de Jaboticabal, SP pel ofornecimento dos dados daradiação solar.

REFERÊNCIAS

Acra, A.;Raffoul,Z:; Karahagopian, Y.Solar disinfection of drinking water and oral rehydration solutions. Paris: UNICEF, 1984.

Acra, A.;Jurdi, M.; Muallem, H.; Karahagopian, Y.W ater disinfection by solar radiation. Otawwa: International Development Research Centre, 1990.

Amaral ,L.A.;RossiJunior,O.D.;N AderFILho,A.;A leXandre, A.V. A valiação da qualidade higiênico-sanitária da água de poços rasos localizados em área urbana: 
utilização decolifagosem comparação com indicadores bacterianos de poluição fecal. Revista de Saúde Pública, v.28, n.5, p.345-348, 1994.

Amaral ,L.A.;Souza,M.C.I.;Barros,L.S.S.;RossIJúnIor,O.D.; Nader FILHo,A.Características microbiológicaseteor denitratos da água de consumo humano esuíno em propriedades rurais situadas na região nordeste do estado deSão Paulo.In:ENCONTRO NACIONALDE MICROBIOLOGIA AMBIENTAL, 6., 2000, Recife. A nais. Recife, 2000. p.69.

American Public Health Association. Standardmethods for examinationn of water and wastewater. 18.ed. Washington DC: A PHA Publication Office, 1992.

Bates, A.J. Water as consumed and its impact on the consumer - do weunderstand thevariables? Food and Chemical Toxocology, v.38, p.29-36, 2000.

BA UDISOVA , D. Evaluation of E. coli asthemain indicator of faecal pollution. W ater Science Technology, v.35, n.11, p.333, 1997.

Bergeisen, G.H.;H Inds, M.W.;SkAGgs, J.W. A waterborne outbresk of hepatitis A in M eade County, Kenticky. A merican J ournal of Public H ealth, v.75, n.2, p.161-164, 1985.

BRA SIL . M inistério daSaúde. Portarian.518,de25demarço de 2004. Norma de qual idade da água de consumo humano. Diário O ficial da U nião, Brasília, 26 de mar. 2004. Seção 1, p.266.

Cason, E.; Greiman, L.; Reynolds, D. Bacterial species isolated from well water in Southern Illinois.D airy, Food and Environmental Sanitation, v.11, n.11, p.645649, 1991.

Conroy,R.M.;M eegan ,M.E.;J oyce, T.;M cGuigan ,K.;Bames, J.Solar disinfection of water reducesdiarrhoeal disease: an update. A rchives of D isease Childrens, v.81, n.4, p.337-338, 1999.

Conroy,R.M.;M eegan,M.E.;J oyce,T,;M cGuigan,K.;Bames, J. Solar disinfection of drinking water protects against cholera in children under 6 years of age. A rchives of D isease Childrens, v.85, p.293-295, 2001.

Dan, T.B.B.; Wrnne, D.; Manos, Y. Survival of enteric bacteria and viruses in lake Kinment, Israel. Water Research, v.31, p.2755, 1997.

Dennis,D.T.;Smith,R.P.;W elch, J.J.;Chute,C.G.;A nderson, B.; H ERNDON , J.L.; $V$ ON REYN, C.F. Endemicgiardiasisin $\mathrm{N}$ ew Hampshire; a case control study of environmental risks. Journal of Infection D iseases, v.167, n.6, p.1391-1395, 1993.

Embil , J.A.;Pereira, L.H.;White, F.M.;Garner, J.B.;M anuel, F.R. Prevalence of A scaris lumbricoides infection in a small Nova Scotian community. A merican Journal of Tropical M edicine, v.33, n.4, p.595-598, 1984.

Galbraith, N.S.;Barret, N.J.; SA tbWell-SMith, R. Water and disease after Croydon. A review of waterborneand water associates disease in UK, 1937-1986. Journal Institituteof $W$ ater \& Environment $M$ anagement, n.1,p.721, 1987.
GRA Bow, W. Waterbornediseases: U pdateon water quality assessmentand control. W ater SA , v.22, n.2, p.193-202, 1996.

Hoffman, F.L.;Garcia-Cruz,C.H.;VInturin, T.M Levantamentodascaracterísticasmicrobiológicasdaáguaproveniente detrêspoçosartesianosdacidadedeSãoJ osédoRioPretoSP. HigieneA limentar ,v.8, n.34, p.36-38, 1994.

Issac-Marquez,A.P.;Lezama-Davila, C.M.;Ku-Pech, R.P.; TAMAY-SEGoviA,P.Calidad sanitariadelossuministros de agua para consumo humano en Campeche. Salud Publica de M exico, v.36, n.6, p.655-661, 1994.

Jorce, T.M...;McGuigan ,K.G.;Elmore-Meegan ,M.;C onroy, R.M. Inactiavtion of fecal bacteriain drinking water by solar heating. A pplied and Environmental M icrobiology, v.62, n.2, p.399-402, 1996.

KeHOE,M.R.;BARER,L.O.M cGUIGAN ,K.G. Batch processsolar disinfection is na efficient means of disinfecting drinking water contaminated withShigelladysenteriae type I.S.C. Letters in A pplied M icrobiology, v.38, n.5, p.410, 2004.

MacGuigan, K.G.,J oyce ,T.M.;C onroy,R.M.;Gillespie,J.B.; Elm ORe-MeEgan ,M . Solar disinfection of drinkingwater contained intransparenteplasticbottles: characterizing the bacterial inactivation process. Journal of A pplied M icrobiology, v.84, p.1138-1148, 1998.

PINFOLD, J.V. Faecal contamination of water and fingertiprinsesasamethod for evaluating theeffect of low cost water supply and sanitation activies on faecal-oral diseasetransmission. II. A hygieneintervention study in rural north-est Thailand. E pidemiology and Infection , v.105, p.377-380, 1990.

Pfammatter, R.\& Wegelin, M. Solar water disinfection: Evaluation of field tests carrie out in Cali, Colombia. Cali: Internal Monitoring Report, 1993.

ReEd, R.H.; MANI, S.K.; MeYER, V. Solar photo-oxidative disinfection in drinking water: preliminary field observations. Letters A pplied M icrobiology, v.30, n.6, p.432-436, 2000.

RIJAL,G.K.\&F UJIOKA ,R.S.Synergisticeffect of solar radiation and solar heating to disinfect drinking water sources. W ater Scienceand Techn ol ogy, v.43, n.12, p.155-162, 2001.

Steel, R.G.D. \& Torrie, J.H. Principles and procedures of statistics. New York: Mc Graw, 1960. 481p.

Sworobuk, J.E.;L aw, C.B.;BissonetTE, G.K. Assesmentof the bacteriological quality of rural groundwater supplies in N orthen WestVirginia.W ater, A ir, and Soil Pollution, v.36, p.163-170, 1987.

Wegelin, M; Canonica, S.;M ech sner, K.; Fleischmann, T.; Pesaro, F;:M etzler, A. Solar water disinfection:scope of theprocess and analysis of radiation experiments. Journal W ater SRT-A cqua, v.43, n.3, p.154-169, 1994.

Recebido em 12/ 12/ 05

A ceito em 9/ 2/ 06 